\title{
Trigonometric Method of Computing the Coordinates of Invisible Targets in Functional Neurosurgery
}

\author{
Franco Ammannati a Lorenzo Bordia Pasquale Mennonna ${ }^{a}$ \\ Paolo Gronchib \\ aUnità Operativa di Neurochirurgia, Azienda Ospedaliera Careggi, Firenze, and \\ bIstituto di Analisi Globale e Applicazioni, C.N.R., Firenze, Italy
}

We read, with great interest, the paper by K. Ott 'An Algorithm for the Empirical Determination of Intracranial Stereotactic Targets', Stereotact Funct Neurosurg 1998;71: 29-35.

In the Neurosurgical Department of Florence City Hospital we routinely employ basically the same method of calculation since 1996 for the surgical treatment of Parkinson's disease by deep brain stimulation.

Since December 1996, we have implanted 54 deep electrodes (1 VIM, 10 GPi, 42 STN, 1 in the pontomesencephalic reticular formation for persistent vegetative state) with anatomical postoperative CT and MRI confirmation of the correct position of the electrode.

We autonomously developed this trigonometric method of calculation in close collaboration with mathematicians of the National Research Council of Italy.

Using a CT scan, the $\mathrm{x}, \mathrm{y}, \mathrm{z}$ coordinates of a point which is at a prefixed distance on the three cartesian planes from a reference system are computed. The latter contains the 'origo' from which the distances are measured, and is identified by points of known coordinates. In clinical terms, we define the coordinates of an 'invisible target' (e.g. VIM, GPi, STN) referred to a reference system, namely the intercommissural line (AC-PC) and the foramen of Monro - posterior commissure line (FM-PC), or the midsagittal plane of the third ventricle which contains both of them.

This plane is univocally identified by three points: $A, \mathrm{AC}$, the anterior commissure, which is localized 3-4 mm below the lower border of the foramen of Monro; $P$, PC, the posterior commissure, which can be seen on the slice immediately superior to the quadrigeminal plate or the upper end of the aqueduct, and inferior to the pineal calcification: $I$, the

\begin{tabular}{|c|c|c|}
\hline KARGER & $\begin{array}{l}\text { () 2000 S. Karger AG, Basel } \\
1011-6125 / 99 / 0721-0070 \$ 17.50 / 0\end{array}$ & $\begin{array}{l}\text { Dr. Franco Ammannati } \\
\text { Unità Operativa di Neurochirurgia }\end{array}$ \\
\hline Fax + 4161306 1234 & & Azienda Ospedaliera Careggi, Viale G.B. Morgagni, 85 \\
\hline $\begin{array}{l}\text { E-Mail karger@karger.ch } \\
\text { www.karger.com }\end{array}$ & $\begin{array}{l}\text { Accessible online at: } \\
\text { www.karger.com/journals/sfn }\end{array}$ & $\begin{array}{l}\text { I-50134 Firenze (Italy) } \\
\text { Tel./Fax }+390554277481\end{array}$ \\
\hline
\end{tabular}


infundibular recess, which is visualized in the center of the lowermost part of the third ventricle; a fourth point, $F$, the postero-inferior border of the foramen of Monro may be added for double check.

The coordinates of point $T$, the 'invisible target', are computed: for this the formulas listed below are used, where the values of the distances from the reference system are implemented; the numerical values are codified by standard stereotactic atlases and are validated by surgical experience.

$$
\begin{aligned}
& A \equiv\left(A_{x}, A_{y}, A_{z}\right) \\
& P \equiv\left(P_{x}, P_{y}, P_{z}\right) \\
& I \equiv\left(I_{x}, I_{y}, I_{z}\right) \\
& M \equiv\left(\frac{A_{x}+P_{x}}{2}, \frac{A_{y}+P_{y}}{2}, \frac{A_{z}+P_{z}}{2}\right) \\
& \vec{u}=\frac{(A-P) \wedge(I-P)}{|(A-P) \wedge(I-P)|} \\
& \vec{v}=\frac{(A-P)}{|A-P|} \\
& \vec{w}=\vec{u} \wedge \vec{v}=\frac{|A-P|^{2}(I-P)-\langle A-P, I-P\rangle(A-P)}{|(A-P) \wedge(I-P)| \cdot|A-P|} \\
& T-M=x \vec{u}+y \vec{v}+z \vec{w} \\
& l=|A-P|=\sqrt{\left(A_{x}-P_{x}\right)^{2}+\left(A_{y}-P_{y}\right)^{2}+\left(A_{z}-P_{z}\right)^{2}} \\
& m=|I-P|=\sqrt{\left(I_{x}-P_{x}\right)^{2}+\left(I_{y}-P_{y}\right)^{2}+\left(I_{z}-P_{z}\right)^{2}} \\
& S=\langle A-P, I-P\rangle=\text { scalar product of } A-P \text { and } I-P= \\
& =\left(A_{x}-P_{x}\right)\left(I_{x}-P_{x}\right)+\left(A_{y}-P_{y}\right)\left(I_{y}-P_{y}\right)+\left(A_{z}-P_{z}\right)\left(I_{z}-P_{z}\right) \\
& a=\frac{\sqrt{l^{2} m^{2}-s^{2}}}{2}=\text { area of the triangle } A P I \\
& C=\frac{2 a y-s z}{2 l a} ; D=\frac{l z}{2 a} ; E=\frac{x}{2 a}
\end{aligned}
$$

Then the coordinates of the target are given by:

$$
\begin{aligned}
& T_{x}=\frac{A_{x}+P_{x}}{2}+C\left(A_{x}-P_{x}\right)+D\left(I_{\mathrm{x}}-P_{\mathrm{x}}\right)+E\left[\left(A_{y}-P_{y}\right)\left(I_{z}-P_{z}\right)-\left(A_{z}-P_{z}\right)\left(I_{y}-P_{y}\right)\right] \\
& T_{y}=\frac{A_{y}+P_{y}}{2}+C\left(A_{y}-P_{y}\right)+D\left(I_{y}-P_{y}\right)+E\left[\left(A_{z}-P_{z}\right)\left(I_{x}-P_{x}\right)-\left(A_{x}-P_{x}\right)\left(I_{z}-P_{z}\right)\right] \\
& T_{z}=\frac{A_{z}+P_{z}}{2}+C\left(A_{z}-P_{z}\right)+D\left(I_{z}-P_{z}\right)+E\left[\left(A_{x}-P_{x}\right)\left(I_{y}-P_{y}\right)-\left(A_{y}-P_{y}\right)\left(I_{x}-P_{x}\right)\right]
\end{aligned}
$$

We protected the relative software, by Copyright, at the Italian Society of Authors and Editors. 
From the clinical point of view, we are satisfied as to the accuracy of this method. We stress the necessity of clinical and neurophysiological intraoperative control by means of stimulation and recording. This letter is to inform you and to emphasize that mathematics are always the same all over the world.

\section{References}

1 Ammannati F, Bordi L, Mennonna P, Ronchi PG, Campi S, Tesi G: Double Method of Calculation (Vectorial and Trigonometric) of Invisible Targets. Coordinates for Functional Neurosurgery. Acta Neurochir 1996;138:615.

2 Scotto di Luzio A, Ammannati F, Marini P, Mennonna P: Electrical Stimulation of the STN in Parkinson Disease. Neurology 1999;52(suppl 2):A404.

3 Ammannati F, Giordano GP, Scotto di Luzio A, Mennonna P: Calcolo trigonometrico delle coordinate stereotassiche TC nel Morbo di Parkinson. Rivista Neuroradiologia 1998;11:43-50. 